\title{
varia
}

\section{Rogelio López Cuenca: acciones y crítica en la práctica artística contemporánea}

\author{
Caterina Iaquinta \\ Fondazione Baruchello. Università di Roma La Sapienza
}

Rogelio López Cuenca (Málaga, 1959) ha desarrollado un camino artístico orientado hacia la observación crítica de los lenguajes mediáticos y en las modalidades normalizadas y subliminales de la comunicación e información de masas: a través de aproximaciones y yuxtaposiciones desorientadoras, López Cuenca reconstruye artísticamente esos mensajes para que recobren de nuevo su eficacia.

Esta entrevista a Rogelio López Cuenca se realizó para el seminario "ROMA77" que el artista dio en la Fundación Baruchello de Roma, cuyo proyecto fue www.mappadiroma.it.

Para empezar esta entrevista... puedes contar algo sobre tu pasado: ¿Cuándo empezaste a trabajar como ‘artista’? ¿En España, en qué contexto artístico te encontrabas?

Mis estudios son en lingüística. Entré en la universidad en 1977 y acabé mis estudios en 1982, precisamente los años que van de la legalización del Partido Comunista al primer gobierno socialista desde la Guerra Civil, pero también el periodo que va de la efervescencia libertaria hasta el inicio del fenómeno de desmovilización política que se llamó 'el desencanto'. Por entonces me consideraba un poeta y mis intenciones más o menos fundadas eran las de convertirme en escritor. En ese tiempo conocí, en el interior de las clases, las literaturas de vanguardia (y de ahí, inmediatamente, su situación dentro de las Vanguardias Históricas en las demás artes, pero no desde el punto de vista académico, de la Historia del Arte) y, por otro lado, en la calle, entré en contacto con otra gente, más o menos también anárquicos o 'desencantados' de la militancia política tradicional y comenzamos a llevar a cabo acciones, graffiti... todo muy provocador, irónico y, sobre todo, técnicamente, muy punk (es decir, prácticamente sin ninguna técnica). También con otros chicos más jóvenes, con los que intentamos también hacer música (con ese mismo espíritu punk, sin saber nada casi, sólo con el deseo de hacer, de estar juntos y divertirnos, de vivir, en suma). Pero inmediatamente también comenzaba la institucionalización de 'la movida': los responsables de incipientes instituciones culturales públicas, bastante desorientados acerca de qué había que hacer, de cómo conjugar la devoción a las vacas sagradas del arte del (anti)franquismo con todo lo nuevo e irreverente que estaba pasando, comenzaron a ofrecernos la posibilidad de participar en eventos, 


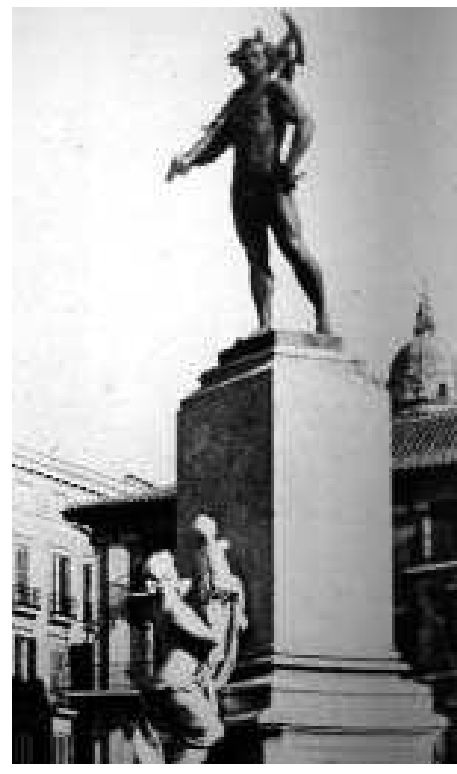

1. Sin Larios (1992). exposiciones, etc. $\mathrm{Y}$ eso hemos hecho; ahora creo que de un modo demasiado acrítico: nos bastaba el papel de 'enfants terribles' que se burlaban de los mayores y de su orden. Pero creo que donde residía la mayor fuerza de estas actitudes, acciones y producción de artefactos diversos era precisamente en la falta de conciencia de estar haciendo 'arte', movidos más bien por el deseo de hacer cosas, las que fueran, no motivadas, por las ganas de intervenir en el entorno, es decir, las ganas de estar juntos, de con-vivir, de vivir intensamente la existencia.

En tus trabajos tales como Sin Larios (1992) [1], las series de los carteles indicadores, de las señales (1990-2000) [2], Nerja Once (2004)... sorprende la actitud crítica e irónica que hay en las imágenes y que recogen 'informaciones' (como mensajes publicitarios...) a las que todo el mundo está sometido sin saberlo. ¿Qué capta tu atención?

Frente a los discursos de la Autoridad, la ironía ha sido históricamente un recurso tradicional de los excluidos, de los extraños al Poder - pensemos en los chistes, la parodia, el carnaval-... Creo que esa distancia, la clara percepción de la exclusión, es la que permite descubrir la mitificación, el carácter artificial, construido, de todo aquello que pretende imponerse como inevitable, como 'natural'. En este sentido, las culturas populares se podría decir que gozan de una innata desconfianza, de un escepticismo extremadamente despierto respecto a los seductores discursos del Poder.

Tengo la sensación cada vez más fuerte de encontrar en los aspectos más marginales de las tradiciones de culturas populares (es decir, en aquellos tan esquivos que han conseguido evitar su normalización folklórica, su recuperación como espectáculo) formidables ejemplos de resistencia y de desafío. Y si atendemos a la progresiva neutralización y banalización de gran parte de la ensimismada maquinaria de producción de Alta Cultura, me parece lógico que las estrategias antagonistas se muevan en dirección a otros modelos más horizontales, participativos, dialógicos, propios de la tradición de las culturas populares, alejadas tanto de la autoría como del autoritarismo.

Recientemente has afirmado que: "el trabajo, una vez expuesto es una señal que circula, deja de pertenecer a quien lo ha creado, que se transforma en un lector 


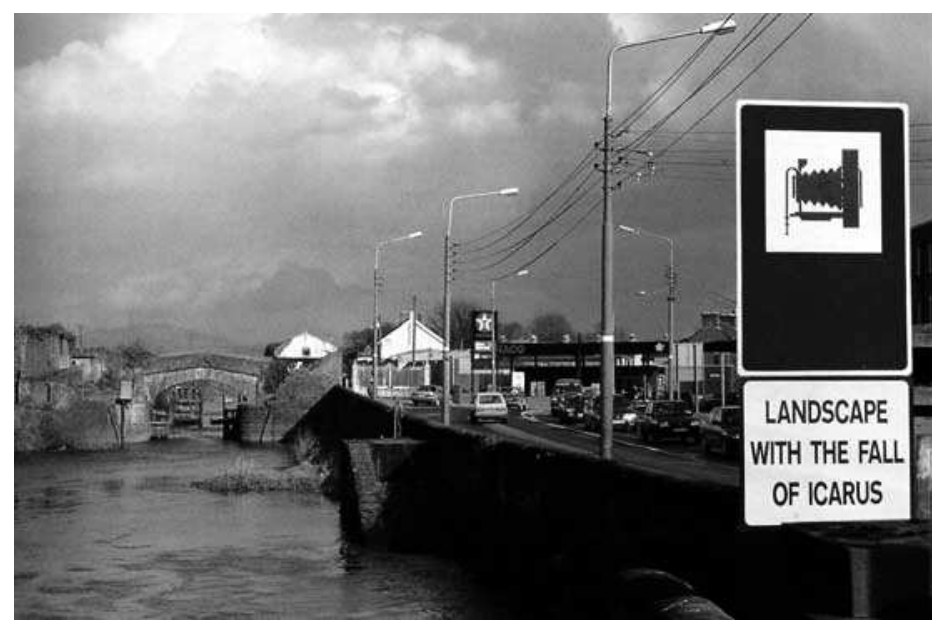

2. Nerja once (2004).

de ese mismo texto". La 'distancia' y el extrañamiento que tu consideras como elementos importantes para una lectura crítica e 'incontaminada' de los sistemas de producción cultural y del poder, ¿devienen premisas y objetivos de un trabajo artístico que implica una puesta en cuestión del autor mismo?

Permíteme que me detenga en el término 'incontaminado'. No me parece interesante - o dudo incluso de hasta qué punto sea posible- la consideración de la obra en sí misma. El pretendidamente inmaculado museo, el impoluto cubo blanco de la sala de exposiciones, precisamente por querer escenificar el aislamiento de la obra de arte, esa misma supresión del contexto, lo que hace es sustituirlo por otro, que produce, reproduce y transmite contenidos ideológicos muy concretos, acerca del carácter excepcional de la obra de arte, de su superioridad, de su estar por encima de las circunstancias espacio-temporales de la vida ordinaria. Yo defiendo una consideración de la obra de arte como producto lingüístico, como fruto de lenguaje, es decir, como algo necesariamente colectivo, social... que solamente cobra sentido en su circulación, en su comunicación, al ser compartida. La obra es un signo y, como tal, su significado es cambiante a lo largo del tiempo y dependiendo de los diferentes contextos en los que aparece y con los que entra en relación.

Hoy el mercado del turismo ha transformado el espacio urbano. El arte y la arquitectura ¿Qué relación mantienen con este nuevo concepto de turismo? ¿Cuál es el contexto en el que tienen que operar?

La arquitectura ha sido siempre la más poderosa de las artes, en tanto que 
construye el espacio en que vamos a vivir, y no sólo físicamente sino también de modo simbólico, establece las jerarquías del escenario y prefija los límites y las normas de los acontecimientos. Actualmente la arquitectura - a través del selecto elenco de arquitectos estrella - juega un rol central en la fabricación de iconos para las ciudades globales que compiten por ganar visibilidad en el mercado de las imágenes. Y no por casualidad suele tratarse de centros de arte o cultura, museos, auditorios, dispositivos ligados a la exhibición de 'cultura', como en otro tiempo lo fueron otros aparatos de control social: catedrales, palacios, hospitales, cuarteles, manicomios... el poder se ejerce desde otros espacios, ligados a la comunicación, a la información, a la cultura, o mejor dicho, al consumo de la misma. El turismo, más que una mera sección especializada del consumismo, parece ser el último y definitivo de los grandes 'ismos'. El objetivo parece que es hacer de la ciudad un museo y de los ciudadanos, turistas de sí mimos. Toda la experiencia cultural pasaría por ese filtro que homogeneiza, reduce, aplana lo real, suprimiendo la complejidad, lo cambiante, lo vivo, prefijando las posibles relaciones sociales, haciendo mercancía de la vida misma. En ese campo es donde el rol de la arquitectura y el urbanismo devienen centrales, tanto a la hora de crear imágenes-pantalla, tautológicos iconos mediáticos que legitiman el turismo - esa lectura del mundo superficial, simplificada, efímera, banalcomo el único espacio posible de la experiencia.

Bernard Tschumi, en el texto Architecture and Disjunction, al comienzo de la secunda parte, "La violencia de la arquitectura"1, afirma:

"1- No hay arquitectura sin acción, no hay arquitectura sin eventos, no hay arquitectura sin programa.

\section{2- Por extensión, no hay arquitectura sin violencia."}

¿Te parece que la idea de alguna forma de violencia unida a la arquitectura podría contener estos aspectos que has subrayado, así como podría ser para el poder mediático que está en condiciones de crear 'eventos', de borrar o releer la Historia...?

Está claro que no podemos ni imaginarnos una arquitectura ajena a la violencia, a la destrucción - la arquitectura construye, más que sobre el pasado, contra él, cancelándolo, imponiéndose sobre el presente y pretendiendo resolver el futuro. Y esa violencia no se ejerce sólo de un modo físico, directo, sobre el territorio, sino sobre las relaciones sociales que éste sustenta, e igualmente sobre la memoria, las múltiples memorias, ya sea mediante la aplicación de la tabula rasa modernista que considera la ciudad como una página en blanco, ya sea a través de un historicismo consolador, anestésico, edulcorante... Hoy no podemos dejar de ver tanto a una como a otra en su relación con la producción turística, con el incremento del número de visi-

1 TSCHUMY Bernard. Architettura e disgiunzione ,(1996), Bologna, Pendragon, 2005. Cap. "La violenza dell'architettura", págs. 97-110 
tantes y con el impacto mediático. Las operaciones de marketing político, la celebración de grandes acontecimientos mediáticos encuentran en la maquinaria arquitectónica contemporánea un vehículo perfectamente adaptado a las necesidades de la propaganda institucional -mera variable temática de la publicidad consumista.

La arquitectura puede hoy ofrecer objetos -o imágenes - de usar y tirar, perfecta y rápidamente intercambiables, respondiendo a las necesidades de un mercado muy dinámico y cambiante. El arquitecto se percibiría finalmente como un elemento integrado en la industria cultural, concebida ésta como un dispositivo central específico en el aparato de producción de servicios, de tercerización de la economía, de la 'turistización' de las ciudades.

En tus últimos trabajos conectas el presente y la memoria, la visión oficial y alternativa de los hechos, la periferia y el centro. Cómo se sitúa la Historia en esta perspectiva ¿Como artista, qué uso piensas se le podría dar, si por Historia entendemos no un campo neutro, una sucesión lineal y regular de hechos/eventos, sino procesos en devenir, mecanismos a través de los cuales la historia se produce y provoca a su vez ideología, referencias, falsificación?

Dentro de la obsesión del turismo cultural por 'poner en el mapa' a las ciudades y junto al programa de producción cíclica de eventos para la renovación de su imagen-mercancía en pugna por atraer los flujos de capital, la ciudad, los gestores de la ciudad-empresa, de la ciudad-espectáculo, buscan en su pasado los rasgos distintivos susceptibles de añadir capital simbólico a su imagen de marca, y para ello se seleccionan determinados bienes culturales atendiendo a su capacidad de generar beneficios económicos a través de la industria turística. Esta perspectiva mercantilista obliga a la adaptación de la ciudad a las exigencias del entretenimiento estandarizado y la 'disneyficación', lo que conlleva la destrucción del tejido urbano y las relaciones sociales y su sustitución por el consumo como única experiencia posible.

El consumo de lo histórico tiene lugar pues en una especie de tiempo presente continuo, permanente, conformado por una sucesión de hechos mixtificados, silenciados o falsificados a conveniencia, una colección en apariencia aleatoria de acontecimientos sin consecuencias, o sin otra consecuencia que la legitimación el status quo, que se presenta no sólo como preferible, no sólo como el mejor de los mundos posibles, sino también como inevitable.

Con el proyecto Lima/Inmemoriam (2002) [3] has empezado a emplear los mapas para describir e investigar los movimientos históricos y sociales. ¿Consideras ésa una alternativa política del 'obrar artístico' ?

En el trazado de otros mapas, el dibujo de geografías otras, de geografías críticas, el desvelamiento de zonas ocultas, de las áreas 'en blanco', las 'terrae incognitae' de los mapas del mundo... los paisajes excluidos, los itinerarios borrados han sido con una intención claramente política y su restauración también indudablemente lo es; y aún más cuando el trabajo sobre lugares concretos y sobre asuntos espe- 

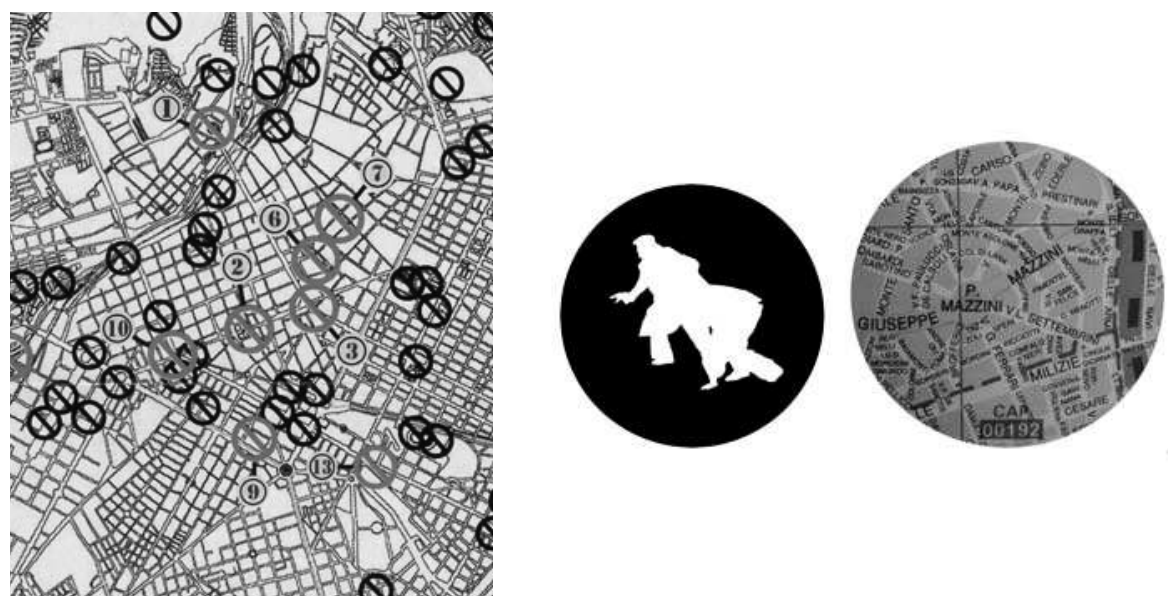

3. Lima/Inmemoriam (2002)

cíficos de su historia muestra su interrelación con el resto del mundo y evidencia el carácter artificial de nuestra percepción del sitio, reconocerlo como interesadamente construido nos plantea también su condición mudable, transformable, es decir, nuestra responsabilidad en la imaginación de otra ciudad, de otra política. Frente al uso oficial de los mapas como instrumento policial-militar (fuentes de información previa indispensable para la conquista y el control del territorio) estas cartografías menores, paralelas, alternativas, constituyen no sólo una reivindicación de la complejidad de lo real frente a la excluyente historia oficial, sino también, en tanto que lenguaje alternativo, propuestas de otros modos de vida.

La Fondazione Baruchello (Roma, Italia) hace tiempo que presta particular atención a la experimentación y a la pluralidad como formas de modalidad de producción artística. Quizá hoy una posibilidad de interrumpir el consumo artístico, su vacuidad y su carácter comercial radique en dirigirse a la realidad, situando el punto de vista en un plano social y político. Pero, entonces ¿dónde se sitúa la investigación artística?

No creo que tenga sentido diferenciar de un modo excluyente ambos modos de hacer. A mi juicio, tienen mucho más interés los espacios de interferencia, los intersticios, la contaminación, los diversos grados de influencia mutua, de interdependencia... Las relaciones de poder generan formas estéticas, del mismo modo que a la inversa, los modos de representar, de hacer ver, se constituyen como modos de simbolizar poder... o contrapoder. Por otra parte, la crisis del pensamiento moderno ha dado lugar a una diseminación y desbordamiento de territorios, de invasión mutua 
de las zonas antes consideradas específicas de las diversas disciplinas. Mis trabajos creo que no tendrían sentido si en ellos no se experimentase tan formalmente a la vez como en los modos de intercambio de conocimiento (los talleres, los procesos 'largos' de trabajo...), son modos de hacer caracterizados por la contaminación, que no pertenecen tradicionalmente o completamente o exclusivamente al mundo del arte. Además, si bien no es el modelo dominante, existen determinados centros y fundaciones dedicadas al arte contemporáneo, que han sabido alejarse tanto del modelo autoritario del museo decimonónico como evitado convertirse en meras productoras de eventos espectaculares y escenarios de oferta continuada de novedades e impactos mediáticos, instituciones tanto públicas como privadas, que se han constituido en verdaderos espacios de investigación alternativos a la universidad tradicional. 